9. Saha P, Sharma S, Korutla L, Datla SR, Shoja-Taheri F, Mishra R, et al. Circulating exosomes derived from transplanted progenitor cells aid the functional recovery of ischemic myocardium. Sci Transl Med. 2019;11:eaau1168.
10. Bittle GJ, Morales D, Parchment N, Parsell D, Ambastha C, Sharma S, et al. Exosomes isolated from human cardiosphere-derived cells attenuate pressure overload-induced right ventricular dysfunction. J Thorac Cardiovasc Surg. 2021;162:975-86.e6.
See Article page 975

\section{Commentary: An idea with some muscle behind it}

\author{
Danielle Gottlieb Sen, MS, MD, MPH, and \\ Bret A. Mettler, MD
}

Great ideas originate in the muscles.

—Attributed to Thomas A. Edison (1847-1931)

Six of nine species of cold-blooded animals have the capacity to regenerate their hearts during adult life. And even though adult human cardiomyocytes exhibit a nonregenerative response to injury, and subsequent systolic heart failure, many fetal mammals retain a regenerative response and demonstrate cardiomyocyte replication. ${ }^{1}$ For those interested in treating systolic heart failure in children, these encouraging findings have fueled an effort to induce children's hearts to regenerate.

Of specific interest to congenital heart surgeons is the fragile group with single right ventricles (RV), whose outcomes are highly dependent on systolic function of the systemic RV. RV failure is addressed with the limited-supply solution of transplantation, and patients accumulate morbidities and compromised quality of life while awaiting a heart.

The view that the heart muscle cannot regenerate was upended with the discovery that bone marrow-derived stem cells could be utilized to regenerate heart muscle.

\footnotetext{
From the Division of Pediatric Cardiac Surgery, Department of Surgery, Johns Hopkins School of Medicine, Baltimore, Md.

Disclosures: The authors reported no conflicts of interest.

The Journal policy requires editors and reviewers to disclose conflicts of interest and to decline handling or reviewing manuscripts for which they may have a conflict of interest. The editors and reviewers of this article have no conflicts of interest.

Received for publication July 12, 2020; revisions received July 12, 2020; accepted for publication July 14, 2020; available ahead of print July 16, 2020.

Address for reprints: Danielle Gottlieb Sen, MS, MD, MPH, Zayed 7017, 1800 Orleans St, Baltimore, MD 21287 (E-mail: Danielle.gottliebsen@jhmi.edu).

J Thorac Cardiovasc Surg 2021;162:989-90

$0022-5223 / \$ 36.00$

Copyright (C) 2020 by The American Association for Thoracic Surgery

https://doi.org/10.1016/j.jtcvs.2020.07.045
}

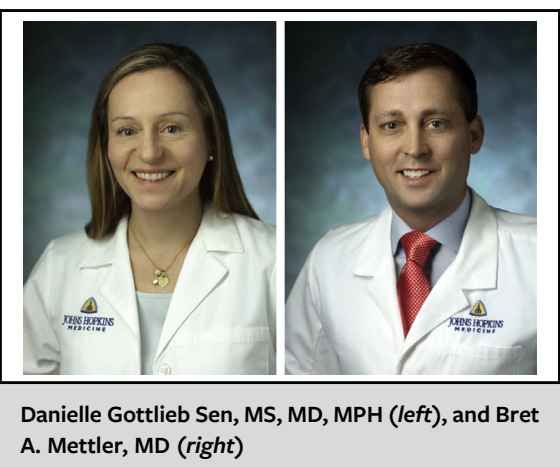

CENTRAL MESSAGE

Regenerative medicine, including stem cell-based therapies aimed at improving myocardial function, is advancing incrementally.

As scientists have established methods for the manipulation of stem cells, tissue-derived mesenchymal stem cells have emerged as an exploitable source of regenerative potential. Further insights into inducible pluripotent stem cells have led to differentiation and maturation techniques that allow the enrichment of cardiomyocyte progenitor populations. The field has subsequently experimented with multiple lineages of stem cells (bone marrow-derived stem cells, umbilical cord-derived stem cells, myocardial resident cardiac progenitor cells, and cardiosphere-derived progenitor cells) and, more recently, the secreted soup of incompletely understood products of cardiospherederived cell differentiation known as exosomes. ${ }^{2}$

Clinical trials have been completed in the field to date with 2 main delivery methods to the myocardium and variability in the timing of intervention, to approach the question of whether there are cell or cell-derived therapies that can ultimately change outcomes in univentricular hearts. Most trials have demonstrated modest improvements in right ventricular fractional area change, between $5 \%$ and $10 \%$, through the duration of the trial. 
In this issue of the Journal, Bittle and colleagues ${ }^{3}$ build on previous work exploring the potential of exosome-mediated paracrine mechanisms to restore systolic function in an animal model of RV pressure load-induced dysfunction. This current study builds on a series of investigations from this group and uses the group's previously established swine pulmonary artery banding model to induce RV dysfunction. ${ }^{4}$

In this study, Bittle and colleagues ${ }^{3}$ separated a "soup" of exosomes into 3 fractions and injected each preparation into the myocardium of the RV at the time of banding. They performed echocardiography at 7 and 28 days, and at the 28day time point, they demonstrated a $6 \%$ increase in right ventricular fractional area change relative to banded controls, with an acceptably minimal inflammatory response. Although this modest increase in right ventricular fractional area change was observed, cardiomyocyte proliferation was not measured, and thus no further mechanistic understanding was attained. The study therefore raises questions about dose and number of injections that might be required for a sustained and clinically significant improvement.

Bittle and colleagues ${ }^{3}$ are to be congratulated for contributing a potentially promising, incremental step in the as-yet elusive goal of improving RV function. Until that juncture, anatomy is destiny, and newts maintain their regenerative advantage.

\section{References}

1. Kimura W, Nakada Y, Sadek HA. Hypoxia-induced myocardial regeneration. J Appl Physiol. 2017;123:1676-81.

2. Fine B, Vunjak-Novakovic G. Heart regeneration in mouse and human: a bioengineering perspective. Curr Opin Physiol. 2020;14:56-63.

3. Bittle GJ, Morales D, Parchment N, Parsell D, Ambastha C, Sharma S, et al. Exosomes isolated from human cardiosphere-derived cells attenuate pressure overload-induced right ventricular dysfunction. J Thorac Cardiovasc Surg. 2021;162:975-86.e6.

4. Kaushal S, Wehman B, Pietris N, Naughton C, Bentzen SM, Bigham G, et al. Study design and rationale for ELPIS: a phase I/IIb randomized pilot study of allogeneic human mesenchymal stem cell injection in patients with hypoplastic left heart syndrome. Am Heart J. 2017;192:48-56.
See Article page 975.

\section{Commentary: \\ Cardiosphere-derived exosomes for single-ventricle heart disease: Are some of the parts greater than the whole?}

\author{
Andrew M. Vekstein, MD, \\ Joseph W. Turek, MD, PhD, and \\ Nicholas D. Andersen, MD
}

Myocardial regeneration remains the holy grail of cardiovascular research in both the adult and pediatric realms.

\footnotetext{
From the Division of Cardiovascular and Thoracic Surgery, Department of Surgery, Duke University Medical Center, Durham, NC.

Disclosures: The authors reported no conflicts of interest.

The Journal policy requires editors and reviewers to disclose conflicts of interest and to decline handling or reviewing manuscripts for which they may have a conflict of interest. The editors and reviewers of this article have no conflicts of interest.

Received for publication Aug 11, 2020; revisions received Aug 11, 2020; accepted for publication Aug 12, 2020; available ahead of print Aug 15, 2020.

Address for reprints: Nicholas D. Andersen, MD, Division of Cardiovascular and Thoracic Surgery, Duke Children's Pediatric \& Congenital Heart Center, 2301 Erwin Rd, DUMC 3443, Durham, NC 27710 (E-mail: nicholas.andersen@ duke.edu).

J Thorac Cardiovasc Surg 2021;162:990-1

0022-5223/\$36.00

Copyright (c) 2020 by The American Association for Thoracic Surgery

https://doi.org/10.1016/j.jtcvs.2020.08.033
}

Check for updates

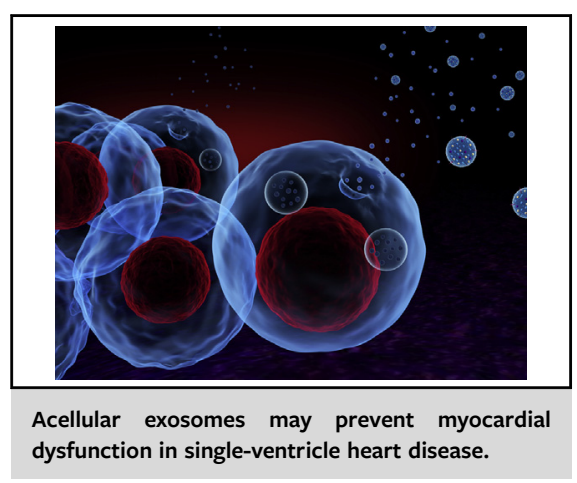

\begin{abstract}
CENTRAL MESSAGE
Intramyocardial injection of acellular exosome preparations from cardiosphere-derived cells may simplify the application of stem cell therapy for patients with single-ventricle heart disease.
\end{abstract}

In pediatric patients with hypoplastic left heart syndrome (HLHS) and other forms of single-ventricle heart disease, progressive dysfunction of the systemic right ventricle (RV) remains a significant barrier to long-term survival. ${ }^{1}$ However, the Transcoronary Infusion of Cardiac 